\title{
Coupling In vitro and In vivo Paradigm Reveals a Dose Dependent Inhibi- tion of Angiogenesis Followed by Initiation of Autophagy by C6-Ceramide
}

\author{
Rishipal R. Bansode ${ }^{1 凶}$, Mohamed Ahmedna ${ }^{1}$, Kurt R. Svoboda², Jack N. Losso ${ }^{3}$ \\ 1. Center of Excellence for Post Harvest Technologies, North Carolina Research Campus, Suite 4222, 500 Laureate Way, \\ Kannapolis, NC 28081, USA. \\ 2. Department of Biological Sciences, Life Science Building, Louisiana State University, Baton Rouge, LA 70803, USA. \\ 3. Department of Food Science, 111 Food Science Building, Louisiana State University, Baton Rouge, LA 70803, USA.
}

$\triangle$ Corresponding author: Center of Excellence for Post Harvest Technologies, North Carolina Research Campus, Suite 4222, 500 Laureate Way, Kannapolis, NC 28081, USA. Tel: 704-250-5707; Fax: 704-250-5709; E-mail: rbansode@ncat.edu

(C) Ivyspring International Publisher. This is an open-access article distributed under the terms of the Creative Commons License (http://creativecommons.org/ licenses/by-nc-nd/3.0/). Reproduction is permitted for personal, noncommercial use, provided that the article is in whole, unmodified, and properly cited.

Received: 2011.04.11; Accepted: 2011.05.06; Published: 2011.05.19

\begin{abstract}
The activity of N-hexanoyl-D-erythro-sphingosine, a C6-ceramide against angiogenesis was tested in vitro and in vivo. The effect of ceramide in inhibiting MCF-7 cancer cells was also determined. The aim of this study was to potentiate the effect of ceramide as anti-angiogenic compound that can regulate tumor induced angiogenesis.

C6-ceramide inhibited vascular endothelial growth factor (VEGF)-induced human umbilical vein endothelial cells (HUVEC) tube formation in a dose-dependent manner within 24 hours. Ceramide at concentrations between 12.5 and $25 \mu \mathrm{M}$ inhibited the viability of MCF-7 cells and reduced VEGF-induced cell migration in 24 hours. At $50 \mu \mathrm{M}$, ceramide induced MCF-7 cell death via autophagy as demonstrated by accumulation of MDC in ceramide-treated MCF-7 vacuoles. The expression of VEGF was reduced and the levels of cathepsin D in MCF-7 increased. In vivo, $50 \mu \mathrm{M}$ ceramide caused a $40 \%$ reduction of new vessel formation in the CAM assay within 24 hours. Zebrafish exposed to 100 - $400 \mu \mathrm{M}$ ceramide had a distinct disruption of blood vessel development at 48 hours post-fertilization. Ceramide-exposed embryos also had primary motoneurons exhibiting abnormal axonal trajectories and ectopic branching. Ceramide induced cell-death was not detected in the zebrafish assay. Collectively, these data indicate that ceramide is a potent anti-angiogenic compound and that the mechanism underlying its anti-angiogenic capabilities does not rely upon the induction of apoptosis.
\end{abstract}

Key words: Ceramide, angiogenesis, zebrafish, MCF-7 cell-line, VEGF, apoptosis, autophagy

\section{Introduction}

Ceramides are sphingolipid-derived, bioactive second messengers. These bioactive compounds are being actively studied as potential chemopreventive molecules because they are intimately involved in the regulation of cancer-cell growth, differentiation, senescence, and cell death $(1,2)$. Evidence indicates that primary and metastatic cancer cells contain less endogenous ceramides compared to normal mucosa from the same patient suggesting that ceramide bio- synthesis processes may be disrupted in cancer cells (3). It has also been shown that radiation-resistant and multi-drug resistant tumor cells do not generate or accumulate ceramides suggesting an alteration in the sphingolipid pathway (4). As a proof of concept, treating cancer cells in vitro with exogenous ceramides invariably results in cycle arrest, senescence, differentiation, apoptosis or autophagy $(1,5,6)$. Moreover, systemic delivery of exogenous ceramide to syngeneic 
Balb/C mice, a mammalian model of breast adenocarcinoma, significantly limits tumor growth (7). Putative mechanisms responsible for ceramide-induced apoptosis of mammary cancer cells include the accumulation of ceramides within the mitochondria which leads to mitochondrial dysfunction, cytochrome $c$ release and caspase activation, dephosphorylation of ceramide-activated protein phosphatase, control of calcium homeostasis, and activation of cathepsin D and protein kinase $C \zeta(1,3$, $5,7-9)$. We have recently demonstrated that ceramide methylaminoethylphosphonate (CMAEPn), a naturally occurring shingophospholipid inhibited the viability of hormone-dependent and -independent breast cancer cells by inactivating VEGF, EGF, and PI3K, which are some of the main signaling pathways associated with the progression of breast cancer (10). These data suggest that addition of exogenous ceramides to tumor cells provides an important mechanism for decreasing tumor cell survival and makes ceramide an attractive bioactive compound for cancer prevention and/or treatment.

Vascular endothelial growth factor (VEGF) plays a major role in the process of vasculogenesis and angiogenesis (11). Aberrant expression of VEGF stimulates angiogenesis in a strict dose-dependent manner in diseases such as inflammation, diabetes mellitus complications, cancer, and cardiovascular diseases (11). VEGF mediates its effect on angiogenesis, under both physiological and pathological conditions, by binding to its receptors KDR/Flk-1 (11). The growth factor is being evaluated as a target for pro- and anti-angiogenesis therapy.

The rapid anatomical development, transparency of the embryo, and rapid circulatory system development similar to mammals make zebrafish an attractive vertebrate model system for analysis of angiogenesis in vivo $(12,13)$. Moreover, recent studies (14) have suggested that many molecules associated with axonal guidance of neurons within the nervous system, also regulate cell migration and apoptosis in normal and tumorigenic tissues. This implies that molecules or agents that can regulate axon guidance during vertebrate CNS development may also be able to arrest the development and progression of cancerous tumors by inhibiting angiogenesis. Signaling cascades involved in nervous system development and angiogenesis share common signaling molecules participating via cross-talk (15). We examined the anti-angiogenic activities of ceramide in vitro using human umbilical endothelial cells (HUVEC), cell migration and autophagy using MCF-7 breast cancer cells. In vivo the activity of ceramide against angiogenesis was evaluated using both the embryonic chick chorioallantoic membrane (CAM) assay and zebrafish model. We examined zebrafish embryogenesis to determine whether angiogenesis and axon guidance are both influenced by ceramide exposure.

\section{Methods}

\section{Cell culture and reagents}

Human umbilical vein endothelial cells (HUVEC) were obtained from Clonetics (Cambrex, Rockland, ME) and grown as per the supplier's instructions. Breast cancer (MCF-7) cells were obtained from American Type Culture Collection (Rockville, MD) and grown as per ATCC's instructions. The cells were passaged once per week at a split of 1:2 and fed once per week. These cells were grown in humidified incubator containing $5 \% \quad \mathrm{CO}_{2} \quad$ at $37^{\circ} \mathrm{C}$. N-hexanoyl-D-erythro-sphingosine (C6-Ceramide) was purchased from Avanti Polar Lipids (Alabaster, $\mathrm{AL}$ ). All other reagents were of analytical grade.

\section{Cell proliferation and cathepsin $\mathrm{D}$ assays}

Confluent cultures of MCF-7 breast cancer cells were seeded on 96-well plates at a density of approximately $2 \times 10^{4}$ cells/well in a total volume of 100 $\mu 1$. The cells were grown for 24 hours prior to exposure. MCF-7 cells were treated by addition of 10 $\mathrm{ng} / \mathrm{ml}$ of $17 \beta$-estradiol prior to the ceramide exposure. Ceramide was dissolved in dimethyl sulfoxide to achieve final concentrations of $0-100 \mu \mathrm{M}$ while making sure that DMSO concentration did not exceed $0.1 \%$. Untreated control cancer cells received less than $0.1 \%$ of dimethyl sulfoxide (DMSO). All experiments were carried out in triplicates. Replicates of culture plates were prepared and incubated for 24 hours in a humidified incubator containing $5 \% \mathrm{CO}_{2}$ at $37^{\circ} \mathrm{C}$. At the end of the incubation period, cell viability and proliferation was determined using the CellTiter 96 $\mathrm{AQ}_{\text {ueous }}$ One solution (Promega, Madison, WI). The plate was read at $490 \mathrm{~nm}$ using a Spectra Max Plus ELISA plate reader (Molecular Devices, Sunnyvale, CA). Cell viability and proliferation were normalized to the levels in untreated control cells to determine the percentage of viable cells. Cathepsin D levels in the supernatants were analyzed using a commercial kit (EMD Biosciences, Inc., San Diego, CA).

\section{Immuno-precipitation and western blot analysis of PI3K/AKT signaling}

MCF-7 cells were plated in 6-well dishes and treated with the $50 \mu \mathrm{mol} / \mathrm{L}$ of ceramide, for 24 hours. After the treatment, the supernatants were removed and the cells were washed with ice cold phosphate buffered saline (PBS). Cell lysis was performed using RIPA buffer (Santa Cruz Biotechnology, Santa Cruz, 
CA) containing a cocktail of protease inhibitors (Santa Cruz Biotechnology, Santa Cruz, CA). Protein concentrations in the cytoplasmic extracts were obtained using BCA protein assay kit (Pierce, Rockford, IL). For immunoprecipitation, $300 \mu \mathrm{g}$ of cytoplasmic extracts was incubated with anti-PI3K at $4^{\circ} \mathrm{C}$ on an end-to end rotator, centrifuged at 10,000x $g$ for $10 \mathrm{~min}$, protein A/G beads were added, the mixture was rotated for 3 hours at $4^{\circ} \mathrm{C}$ and the immunocomplexes were washed three times with lysis buffer. Sodium dodecyl sulfate (SDS) sample buffer was added to the beads, and the beads were incubated at $95^{\circ} \mathrm{C}$ for 5 minutes. The supernatant was then separated by electrophoresis and transferred to a nitrocellulose membrane. The membrane was blocked with 5\% nonfat dry milk in PBS/Tween $20(0.05 \%)$ followed by incubation with an anti-PI3K antibody (1:1000 in 10\% milk/PBS-T). Visualization of the bound primary antibody was done by probing with horseradish peroxidase-conjugated secondary antibodies (1:1000) and that signal was revealed by exposure to a chromogenic detection reagent.

\section{Visualization and quantification of autophagic vacuoles in MCF-7 cells}

MCF-7 cells were treated with $0-50 \mu \mathrm{M}$ of ceramide for 24 hours visualization of autophagic vacuoles, MCF-7 breast cancer cells were grown on coverslips for 24 hours labeled with $0.05 \mathrm{mM}$ monodansylcadaverine (MDC) in PBS at $37^{\circ} \mathrm{C}$ for 10 minutes. After incubation, cells were washed four times with PBS and analyzed using an Axiovert 405M, inverted microscope equipped with epi-fluorescence. For quantification of autophagic vacuoles in cells, cells were plated in 96-well plates and treated with ceramide followed by incubation with $0.05 \mathrm{mM}$ MDC in PBS at $37^{\circ} \mathrm{C}$ for 10 minutes (16). After incubation, cells were washed with PBS four times and collected in $10 \mathrm{mM}$ Tris- $\mathrm{HCl}(\mathrm{pH} 8$ containing $0.1 \%$ Triton X-100). Intracellular MDC was measured at 380/520 nm using Perkin Elmer LS 50B spectro- fluorometer. DNA fluorescence was measured by adding ethidium bromide to a final concentration of $0.2 \mu \mathrm{M}$ and measured at 530/590 nm using Perkin Elmer LS 50B spectrofluorometer.

\section{Cell migration assay}

Cell migration assays were performed in a 96-well disposable chamber (Chemicon Quantitative Cell Migration $\mathrm{QCM}^{\mathrm{TM}}$, catalog number ECM 510) as per the manufacturer's instructions. MCF-7 $\left(1.0 \times 10^{6}\right.$ cells) in $100 \mu$ l of media was added to the membrane. The wells of the feeder tray were loaded with $150 \mu$ of media containing $0.1 \%$ BSA (negative control) or $0.1 \%$ fetal bovine serum and $10 \mathrm{ng} / \mathrm{ml}$ VEGF as chemo-attractants. Plates were incubated in a cell culture incubator at $5 \% \mathrm{CO}_{2}, 37^{\circ} \mathrm{C}$ for 6 hours. MCF-7 cells pretreated with $10-50 \mu \mathrm{M}$ ceramide or DMSO (vehicle) for 24 hours were added to each well. At the end of a 6 hour incubation period, the cells were dislodged from the underside of the membrane using cell detachment buffer and split with lysis buffer along with the dye and $150 \mu$ of the mixture was transferred to a 96-well plate suitable for fluorescence measurements. The plates were read at $480 \mathrm{~nm} / 520 \mathrm{~nm}$ using Perkin Elmer LS 50B spectrofluorometer. Results were normalized to one hundred percent migration of control MCF-7 cells and reported as relative migration.

\section{ELISA assays for VEGF}

MCF-7 $\left(2 \times 10^{6}\right.$ cells per well $)$ cells were plated in 6-well dishes and treated with $0-50 \mu \mathrm{M}$ of ceramide for 24 hours. After the treatment, the supernatants were collected for the quantification of VEGF and cathepsin D. VEGF levels in the supernatants were determined using a commercial sandwich ELISA kit (Chemicon, Temecula, CA).

\section{In Vitro angiogenesis and tube formation Assay}

In vitro angiogenesis assays were performed using a commercially available kit from Chemicon Inc. (catalog ECM 625, Chemicon, Temecula, CA). After preparing the gel matrix, as per the manufacturer's instructions, and allowing it to solidify, $\operatorname{HUVEC~}(1.0 \mathrm{x}$ $10^{4}$ cells in $50 \mu \mathrm{l}$ ) were seeded onto the surface of the polymerized EC Matrix in the presence of $10 \mathrm{ng} / \mathrm{ml}$ of VEGF alone or VEGF and 0-50 $\mu \mathrm{M}$ of ceramide dissolved in DMSO. The plates were incubated at $5 \%$ $\mathrm{CO}_{2}, 37^{\circ} \mathrm{C}$ for 6 hours. Tube formation was inspected and images were photographed using a Nikon color camera mounted to Leitz phase contrast, inverted microscope (10X magnification).

\section{The embryonic chick chorioallantoic membrane (CAM) assay}

Fertilized chicken eggs were obtained from Spafas (Norwich, CT). The shells were cleaned with $70 \%$ ethanol. The eggs were then incubated at $37^{\circ} \mathrm{C}$ for three days. After incubation, the eggs were cleaned with $70 \%$ ethanol, carefully cracked, and the embryos were carefully explanted into sterile Petri dishes and incubated for two days at $37^{\circ} \mathrm{C}$ and $3 \% \mathrm{CO}_{2}$. Fifty-micromolar ceramide (dissolved in DMSO) was applied to a nylon mesh (Tetko, \#3-300/50, $4 \times 4 \mathrm{~mm}$ ) and subsequently freeze dried. The mesh was placed on an outer third of the CAM and the Petri dish containing the CAM was returned to the incubator. Images of both control and exposed CAMs were acquired digitally 24 hours after the onset of the ceramide exposure. The morphology of exposed ves- 
sels was analyzed at later times. The total length of the vessels in each region was measured using the $\mathrm{NIH}$ Image 1.63 program as described by others (17).

\section{Zebrafish embryo collection and ceramide expo- sures}

Embryos were generated by natural pair-wise mating (18). For each mating, 4-5 pairs were set up and an average of 100-150 embryos per pair was generated. Embryos were maintained in embryo medium $(0.2 \mathrm{~g} / 1$ of Instant Ocean Salt in distilled water $)$ at $27-28^{\circ} \mathrm{C}$ for approximately 10 hour before sorting for viability, using both morphology and developmental stage as criteria. Embryos were then dechorionated by enzymatic digestion with $1.4 \mathrm{mg} / \mathrm{ml}$ protease (Sigma, St. Louis, Missouri, USA) for 7-8 minutes at room temperature. The dechorionated embryos were then washed at least ten times in embryo medium. They were then exposed to medium containing $0.2-0.8 \%$ DMSO and ceramide $(100-400 \mu \mathrm{M})$ beginning at $10-14$ hours post fertilization (hpf), the period of development before the vicinity of angiogenic vessels express VEGF ( 19 hpf). After ceramide addition, the embryos were maintained in individual petri dishes at $27-28^{\circ} \mathrm{C}$, until 48-72 hpf. Individual embryos were visually inspected for viability, gross morphological defects, and alterations in heart rate and circulation. Circulation was assayed by visually comparing the movement of blood cells in treated and control embryos to assess the relative blood flow rate. The embryos were visually inspected every six hours following ceramide treatment until $36 \mathrm{hpf}$. Later, the embryos were monitored every hour until $56 \mathrm{hpf}$ to assess the onset of intersegmental blood vessels (ISBV) blood circulation which usually starts between $36-48 \mathrm{hpf}$ and is completed by 56 hpf (12). Each individual embryo was videotaped using a CCD camera mounted to a Zeiss dissecting microscope (Thornwood, NY).

\section{Morphological analysis: vascular development}

In living embryos, intersegmental blood vessel (ISBV) patterning was observed utilizing the transgenic line of zebrafish $\mathbf{T g}($ fli1:EGFP) $y 1$ referred to as Fli-1 from here onward. Fli-1 is an endothelial marker and GFP attached to the Fli-1 promoter aids in the observation of vasculature structure formation of zebrafish during embryogenesis. The Fli-1 line was obtained from the Laboratory of Brant Weinstein at the National Institute of Health, USA. Images of GFP positive, Fli-1 embryos were acquired digitally with an ORCA-ER camera mounted to a Zeiss inverted microscope with epi-fluorescence capabilities. The GFP filter cube on the microscope was used to acquire the GFP fluorescent signal.

Digital images of living embryonic zebrafish from the region caudal to the anal fin were also acquired with bright-field DIC optics with a 40x objective. We imaged 8-10 segments in each analyzed fish. In DMSO control 48hpf embryos, blood flow was easily detected in the both intersegmental veins and arteries. DMSO control and ceramide-exposed embryos were imaged and scored to determine the presence of blood flow in each of those imaged segments. In DMSO control embryos, blood flow was evident in all segments analyzed with DIC optics. Segments in ceramide-exposed embryos often completely lacked blood flow. Those vessels were documented and kept track of in their corresponding images. Those blood vessels lacking blood flow were then analyzed and their diameters quantified separately from the blood vessels that exhibited blood flow. Quantification of vessel diameter was performed using the analysis software provided in Axiovision 4.6.

\section{Morphological analysis: motoneuron development}

For examination of $\mathrm{CaP}$ motoneurons in living embryos exposed to ceramide, embryos of the NBT line were used. In 30-36 hpf embryos of the $\mathrm{Tg}$ (NBT:MAPT-GFP)zc1 transgenic line, GFP can easily be detected in CaP motoneuron axons. The NBT line was kindly provided by Dr. Chi Bin Chien (University of Utah Medical School, Salt Lake City). To examine MiP axon morphology, whole mount immunohistochemistry was performed using a modified version of our previously published immunohistochemistry protocol $(19,20)$. Embryos processed for immunohistochemistry were first fixed in $4 \%$ paraformaldehyde overnight at $4^{\circ} \mathrm{C}$ and then stored in PBS or phosphate buffered saline with Tween 20 (PBST). After this, the embryos were incubated in a primary antibody overnight at $4^{\circ} \mathrm{C}$. The primary antibody znp1, which labels primary motoneuron axons, was used at a dilution of 1:250. The following day, the embryos were washed for $60 \mathrm{~min}$ in PBS buffer and then incubated in a fluorescent secondary antibody, Alexa 546 (1:1000 dilution) for 90 minutes. Embryos were then rinsed with PBST for another $60 \mathrm{~min}$ and prepared for image analysis. Images of stained embryos were acquired digitally with an ORCA-ER camera mounted to a Zeiss inverted microscope with epi-fluorescence capabilities. The $543 \mathrm{~nm}$ filter cube on the microscope was used to acquire the rhodamine fluorescent signal.

\section{Acridine orange staining in zebrafish}

Living embryos (30-36 hpf) were exposed to Acridine Orange $(\mathrm{AO})$ for 60 minutes at room temperature. A working concentration of $5 \mu \mathrm{g} / \mathrm{ml}$ was used with the AO being made in embryo medium. After the hour incubation period, embryos were rinsed 
several times in embryo medium and then transferred to petri dishes containing MS222. Once anesthetized, the embryos were mounted on a slide and images of dying cells in embryos were acquired digitally with an ORCA-ER camera mounted to a Zeiss inverted microscope with epi-fluorescence capabilities. The 543 $\mathrm{nm}$ filter cube on the microscope was used to acquire the rhodamine fluorescent signal.

\section{Statistical Analysis}

All values presented in bar graphs are means \pm standard error of the means (SEM). Kruskall-Wallis analysis of variance was performed to test for significance between control values and experimental values. In some instances where appropriate, a Student T-test was used to test for statistical significance. Significance was assigned if the $p$ value was $<0.05$. In all examples denoted by *, $p$ value is $\leq 0.01$ when comparing experimental values to control values.

\section{Results}

\section{Ceramide induced autophagy, a specific type of cell death}

MCF-7 cells were plated for 24 hours and evaluated for viability in the presence of various concentrations of ceramide. Ceramide inhibited the viability of MCF-7 breast cancer cells in a dose dependent manner. At $12.5 \mu \mathrm{M}$ or less, ceramide did not affect the viability and proliferation of MCF-7 cells. However, at concentrations equal to or above $50 \mu \mathrm{M}$, the viability of MCF-7 cells was inhibited by roughly 75 $\%$. (Figure $1 \mathrm{~A}$ and $1 \mathrm{~B}$ ).
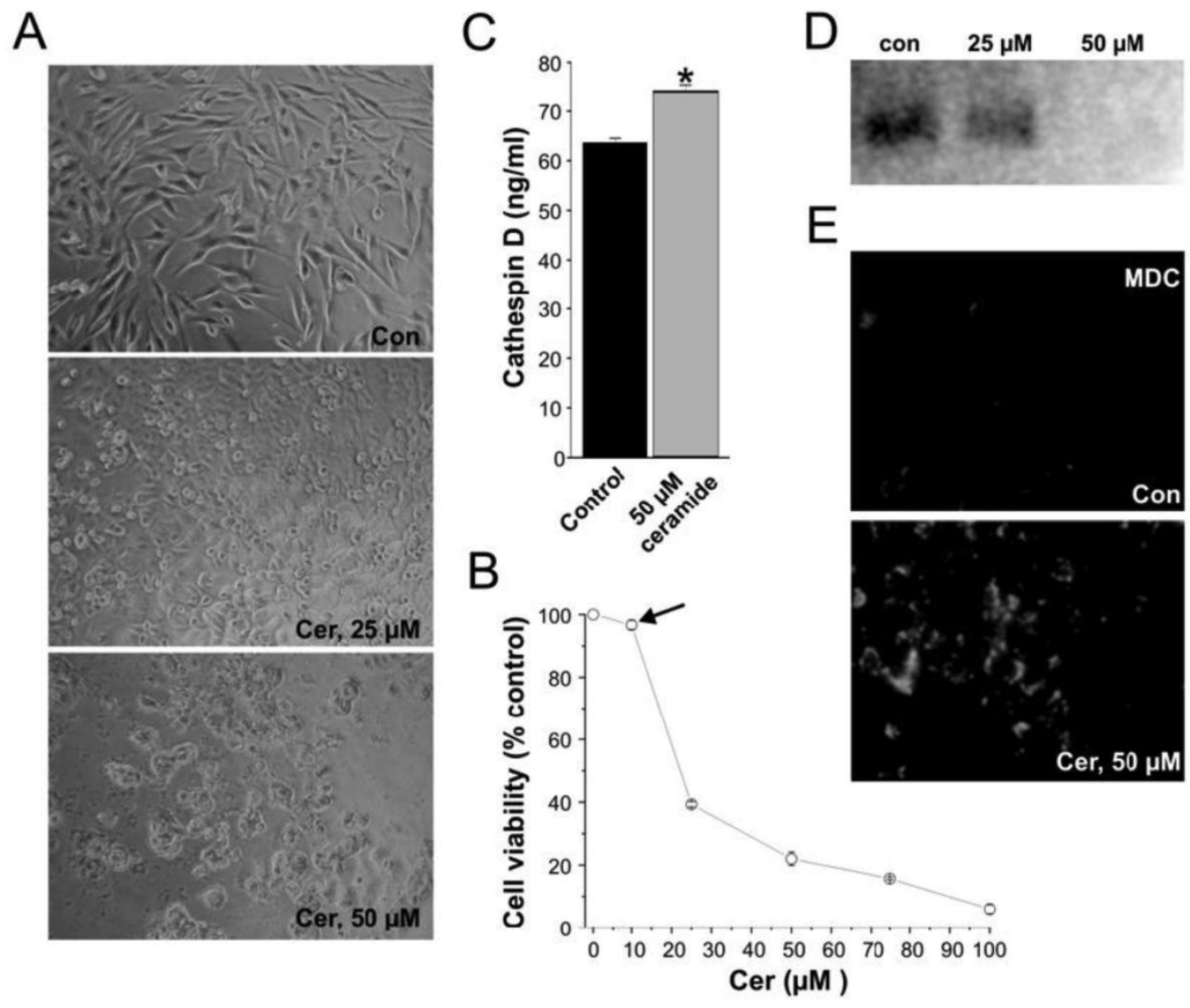

Figure 1. Ceramide exposure affects cell growth and proliferation in vitro. (A) Control MCF-7 cell-line and 25-50 $\mu \mathrm{M}$ ceramide-exposed MCF-7 cell-lines treated for 24 hours. (B) Cell viability quantification illustrating the effect of ceramide on cells of the MCF-7 cell-line treated for 24 hours. Ceramide exposure altered the viability of the MCF-7 cell-lines in a concentration dependent manner. Note that at $12.5 \mu \mathrm{M}$ ceramide, no significant cell death is induced by ceramide (black arrow). (C) Cathepsin D levels in MCF-7 cells exposed to ceramide at a concentration of $50 \mu \mathrm{M}$ for 24 hours. Results are represented as Cathepsin $D$ concentration $(\mathrm{ng} / \mathrm{mL})$. Data are from three experiments conducted in triplicates ( $\left.{ }^{*} \mathrm{p}<0.001\right)$. (D) Westernblot of PI3K protein expression in MCF-7 cells exposed to $25 \mu \mathrm{M}$ and $50 \mu \mathrm{M}$ ceramide for 24 hours. (E) Visualization of monodansylcadaverine (MDC) indicative of autophagic vacuole formation in MCF-7 cells treated with ceramide at $50 \mu \mathrm{M}$ for 24 hours. 
At this concentration, markers of cell death were significantly up-regulated. Ceramides are known to bind and activate cathepsin $\mathrm{D}$ followed by the autocatalytic proteolysis of the $52 \mathrm{kDa}$ isoform to the enzymatically active $48 / 32 \mathrm{kDa}$ isoforms of the enzyme (21-23). Cathepsin D has been implicated in the release of cytochrome $\mathrm{C}$, followed by the activation of caspases and ultimately the induction of cell death (24). The level of cathepsin D was increased following incubation of MCF-7 cells with $50 \mu \mathrm{M}$ ceramide (Figure $1 \mathrm{C})$.

Further analysis revealed that the cell death resulting upon ceramide exposure in MC-7 cells was autophagy. Autophagy is a specific form of cell death characterized the accumulation of monodansylcadaverine (MDC) in mature autophagic vacuoles. Moreover, several signaling pathways, including targets of rapamycin (mTOR), phosphatidylinositol 3-kinase-I (PI3K-I)/ PKB, GTPases, along with calcium and protein synthesis have been shown to play important roles in regulating autophagy. The PI3K family is comprised of three main classes: I, II, and III and all these mediate cellular processes such as growth and survival, entrance into the cell cycle, adhesion, and migration (25). Ceramides inhibit class III PI3K signaling pathways and stimulate beclin I protein which mediate autophagy (6). Ceramides are known to stimulate autophagy by interfering with class I PI3K signaling pathways. Moreover ceramide levels are present at lower levels in cancer cells than normal cells, suggesting that ceramide may be an important factor in the regulation of autophagy (26). The ability of ceramide to down regulate the expression of PI3K was confirmed by western blot. MCF-7 controls showed abundant level of PI3K protein expression whereas MCF-7 cells incubated with $50 \mu \mathrm{M}$ of ceramide exhibited a complete reduction in PI3K expression (Figure 1D).

The accumulation of monodansylcadaverine (MDC) in mature autophagic vacuoles such as autophagolysosomes, but not in the early endosomal compartment is a reliable marker of autophagy (27). Consequently, we utilized monodansylcadaverine staining to detect the presence of autophagic vacuoles and autolysosomes in control and ceramide exposed MCF-7 cells $(16,27)$. In MCF-7 cells treated with 50 $\mu \mathrm{M}$ of $\mathrm{C} 6$ ceramide for 24 hours, the accumulation of monodansylcadaverine was very evident whereas in untreated MCF-7 tumor cells, monodansylcadaverine was not detected (Figure 1E). The fact that no autophagic vacuoles were observed in MCF-7 control cells indicates that ceramide exposure at $50 \mu \mathrm{M}$ caused cell death by autophagy in the exposed MCF-7 cells (16).

\section{Ceramide inhibits migration of $\mathrm{MC7}$-cells in vitro}

Ceramide at concentrations of 12.5 and $25 \mu \mathrm{M}$, inhibited the MCF-7 cells motility in presence of VEGF that served as a chemoattractants (Figure 2A). Endothelial cells migrate by chemotaxis caused by angiogenesis-inducing growth factor such as VEGF. Inhibition of VEGF receptors reduces the migration of endothelial cells towards the chemo-attractant VEGF. Incubation of MCF-7 cells with the ceramide (0-50 $\mu \mathrm{M})$ inhibited VEGF release into the medium in a concentration-dependent manner (Figure 2B). The significant difference between the control and ceramide-treated cells may explain the reduced migration of breast cancer cells towards VEGF as chemo-attractant.

\section{Ceramide inhibits tube formation by endothelial cells}

In the MCF-7 cell lines, ceramide exposure resulted in autophagy at high concentrations. However, at lower concentrations that did not result insubstantial cell death, ceramide exposure significantly reduced cell migration. Because of this, we hypothesized that ceramide exposure could potentially inhibit tube formation in endothelial cells which would suggest that ceramide may ultimately be able to alter angiogenesis via a mechanism not coupled to cell death. To test this, the effect of ceramide exposure on HUVEC was investigated.

On a synthetic basement membrane matrix, human umbilical vein endothelial cells are capable of morphological differentiation into an extensive network of capillary-like structures composed of highly organized three-dimensional cords. The alignment of endothelial cells in capillary-like structures is a functional trait that is typical of angiogenesis. In the presence of $10 \mathrm{ng} / \mathrm{ml}$ of VEGF, human umbilical vein endothelial cells plated on the EC matrix aligned and formed capillary-like structures within 6 hours (Figure 2C). Exposing HUVEC to $25 \mu \mathrm{M}$ ceramide inhibited tube formation within 6 hours as revealed by the capillary-like network within the ECmatrix typical for HUVEC being disrupted (Figure 2C).

Thus, in all of these in vitro assays, ceramide is having an apparent dual effect on cell biology. At concentrations ranging between 12.5 and $25 \mu \mathrm{M}$ ceramide, cell migration and tube formation were affected by ceramide exposure. Importantly, VEGF was also significantly reduced by exposure to $12.5 \mu \mathrm{M}$ ceramide. Remembering that ceramide did not cause a significant decrease in cell viability at this concentration (Figure 1B), it is likely that the inhibition of angiogenesis by ceramide exposure may precede its al- 
ready known effect on cell death, at least in the in vitro assays utilized in this study.

At $50 \mu \mathrm{M}$, the induction of autophagy resulted upon ceramide exposure. Thus, the dose responsiveness of the differing phenotypes revealed a dual mode of action for ceramide. Exposures at low concentrations inhibited tube formation and migration and exposure to high concentrations of ceramide resulted in autophagy.

\section{Ceramide inhibits blood vessel growth in vivo}

Our in vitro data to this point strongly suggested that ceramide may directly influence angiogenesis. To determine if ceramide exposure influenced angio- genesis in vivo, the consequences of ceramide exposure on angiogenesis in two vertebrate models, the embryonic chick chorioallantoic membrane (CAM (28)), and the zebrafish model were investigated. In the in vivo CAM assay, $50 \mu \mathrm{M}$ ceramide caused a significant reduction of embryonic angiogenesis by as much as $40 \%$ within 24 hours. DMSO at $0.1 \%$ as solvent for ceramide had no effect on vessel growth (Figure 3). Ceramide-exposed chorioallantoic membranes exhibited diminished blood vessel development and the blood vessels were also retracted away from the exposed region of embryo. Ceramide exposures longer than 24 hours were deleterious to the developing chick embryo.
A

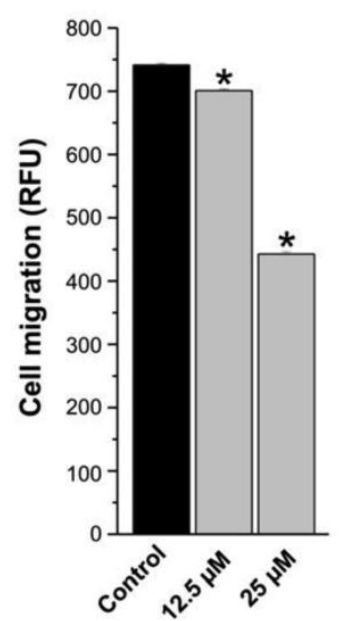

C

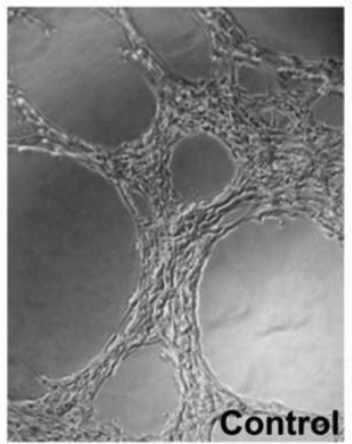

B

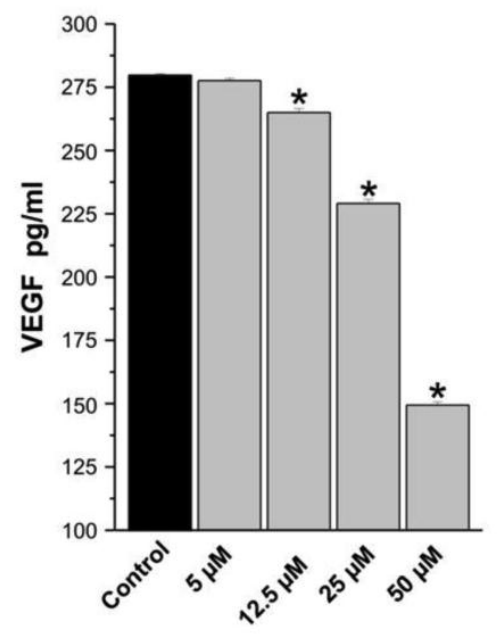

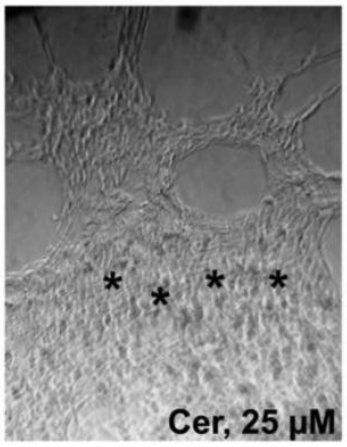

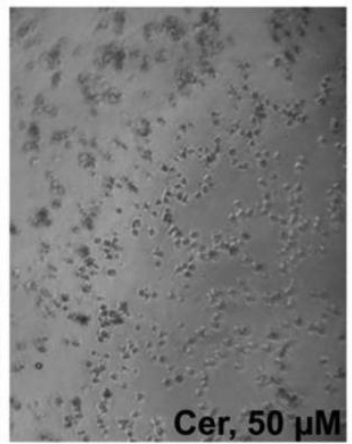

Figure 2. In vitro assays of tumorogenesis and tube formation, consequences of ceramide exposure. (A) Ceramide exposure inhibits cell migration. Results are expressed as percent of control (vehicle-treated cells) and the means of triplicate determinations $\pm \mathrm{SE}$. Data are from one experiment and are representative of three replicated experiments $\left({ }^{*} \mathrm{p}<0.001\right)$. (B) Effect of ceramide exposure $(5 \mu \mathrm{M}-50 \mu \mathrm{M})$ on VEGF expression in MCF-7 cells treated for 24 hours. Results are represented as a VEGF concentration $(\mathrm{pg} / \mathrm{mL})$ after normalization based on cell viability. Data are from three experiments conducted in triplicates $(p<0.001)$. (C) HUVEC containing $10 \mathrm{ng} / \mathrm{ml}$ of VEGF were plated on a Matrigel and they typically aligned forming cord-like structure. The asterisks in the $25 \mu \mathrm{M}$ example denote a region where ceramide induced tube formation has been inhibited. 

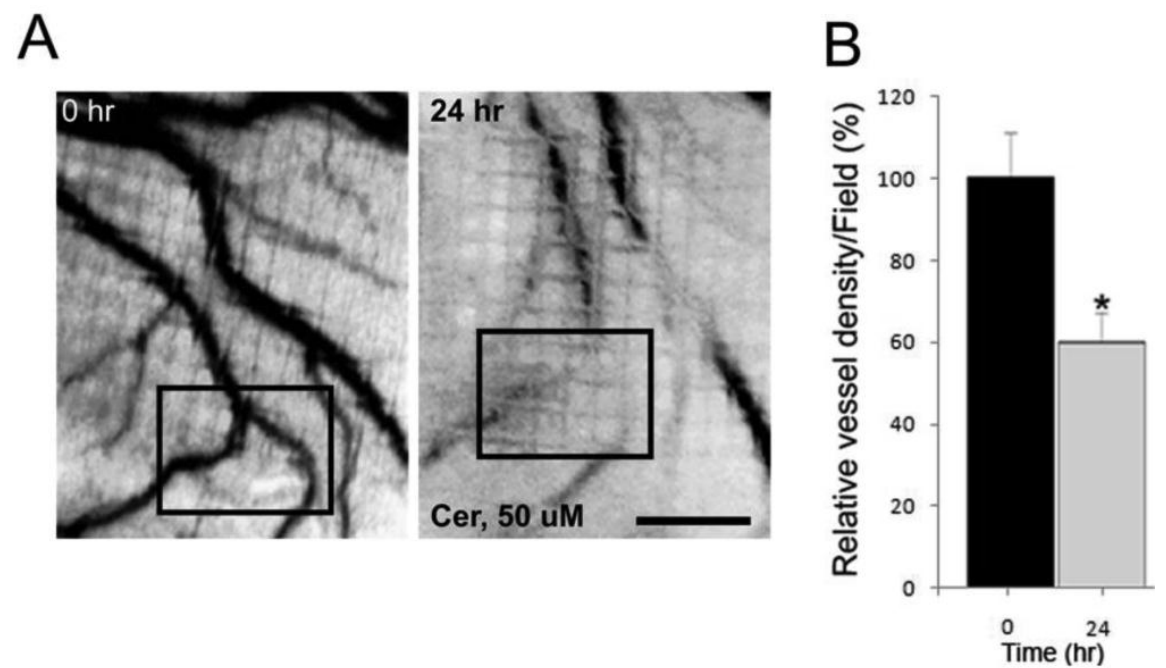

Figure 3. Effect of ceramide exposure on embryonic angiogenesis in the chick chorioallantoic membrane (CAM) assay. (A) Ceramide $(50 \mu \mathrm{M})$ was applied to the surface of the embryonic chick CAM for 24 hours. The blood vessels are easily detected in the CAM at 0 hour prior to the ceramide exposure. The black box denotes a region of interest to allow for comparisons between the image taken at 0 hour and the one taken 24 hours later. (B) The effect of ceramide exposure on blood vessel length during a 24 hours period of development was quantified and presented in bar graph form $\left({ }^{*} p<0.02\right)$. Scale bar $=1.0 \mathrm{~mm}$.

With the effect on angiogenesis in the CAM assay established, we then set out to determine the consequences of ceramide exposure in zebrafish embryos. There are numerous reasons for doing so, but the primary driving force was the fact that other groups had documented a link between angiogenesis and nervous system development $(15,29,30)$. If ceramide exposure was indeed affecting signaling cascades involved with angiogenesis, we hypothesized that ceramide may also have an effect on nervous system development, in this case, axonal path-finding of spinal motoneurons. Since, the zebrafish model is well-established model for studying many aspects of development, extending our studies to a system where we could easily assay blood vessel and neuronal development along with apoptosis was an important next step in this study. In the CAM assay, we could not determine if the anti-angiogenic effects of ceramide were related to ceremide's established ability to induce autophagy. In zebrafish embryos, cell death including autophagy can be analyzed with a wide array of cell biological techniques $(31,32)$. Thus, the utilization of the zebrafish model would let us determine the mechanism by which ceramide inhibits angiogenesis in vivo; either by directly effecting angiogenic pathways or by initiating autophagy which would then result in inhibited angiogenesis.
Toxicology of ceramide exposure in zebrafish: effects on gross morphology and angiogenesis

The ability of zebrafish to tolerate the solvent DMSO, which was used as a carrier for ceramide, was evaluated and no morphological changes were observed at $1 \%$ DMSO. Based on this solubility criteria and an effective concentration of ceramide, a working waterborne concentration of $0.2-0.8 \%$ DMSO as a carrier solvent was established. All subsequent experiments were conducted with ceramide concentrations ranging from $100 \mu \mathrm{M}$ to $400 \mu \mathrm{M}$. The first observable phenotypes were detected at a waterborne exposure concentration of $100 \mu \mathrm{M}$.

Ceramide exposure (14 - $48 \mathrm{hpf}$ ) had no effect on the gross morphology of the zebrafish embryos (Figure $4 \mathrm{~A}$ ). However, exposure caused a complete loss of, or disrupted blood flow in $70 \%$ of the embryos examined ( $n=117 / 166$, embryos that were individually videotaped, Figure 4C, 4D-left panel). This disrupted blood flow was specific for blood flowing through the intersegmental veins (ISVs) and intersegmental arteries (ISAs), collectively referred to as intersegmental blood vessels (ISBVs, Figure 4B). These vessels are located in the mid-trunk region of every segment in zebrafish embryos (Figure 4B, Figure 4C). In contrast to this, blood flow was easily detected in the dorsal aorta and PCV in the ventral region of embryos adjacent to the yolk sac. 
A

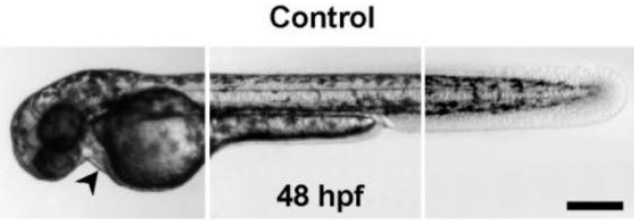

Ceramide

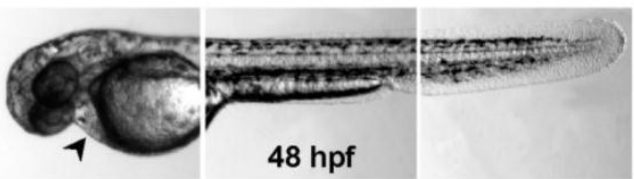

C
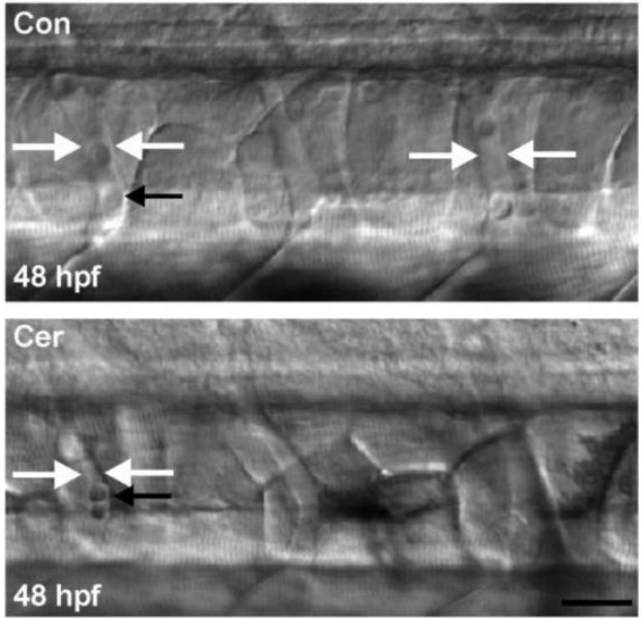

$48 \mathrm{hpf}$
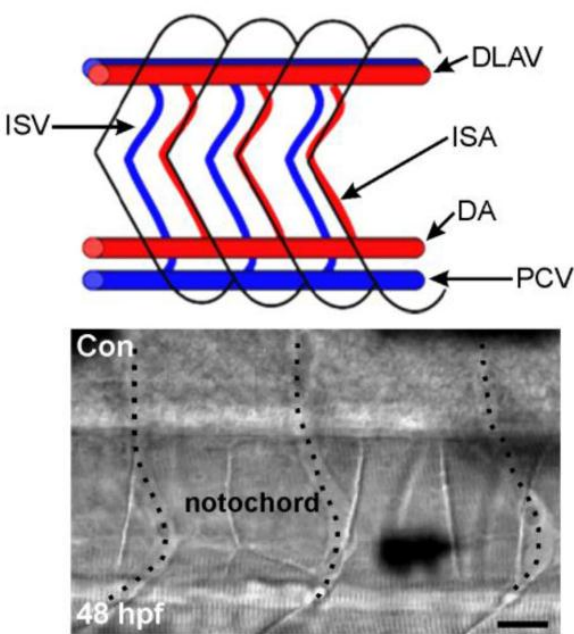

D
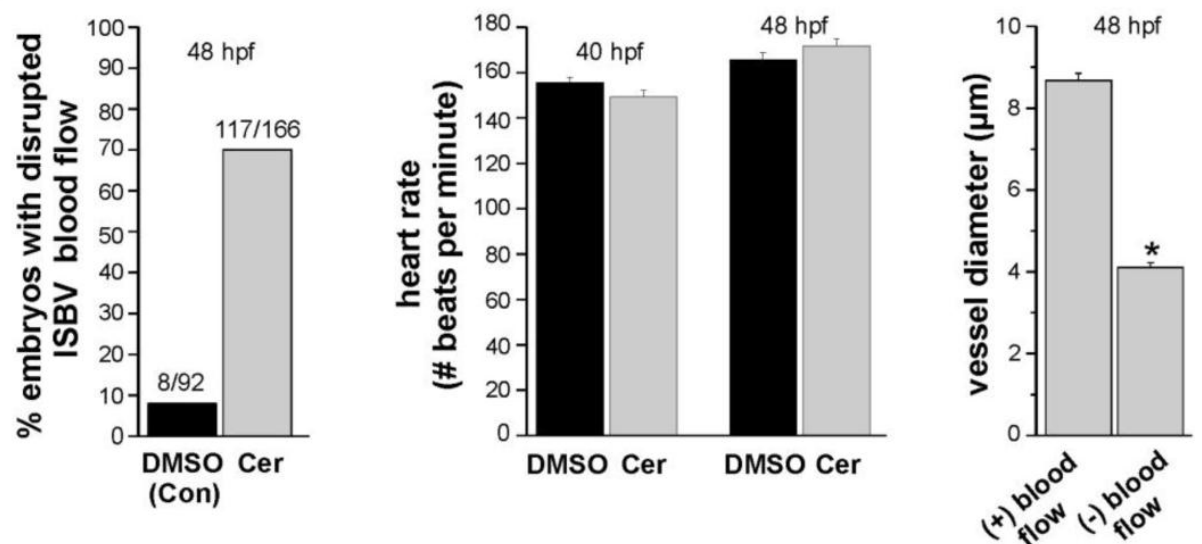

Figure 4. Ceramide effects on zebrafish morphology and blood flow. (A) Composite images of head, mid-trunk, and tail regions of a DMSO-exposed (control) $48 \mathrm{hpf}$ embryo and a composite image of head, mid-trunk and tail regions of $48 \mathrm{hpf}$ embryo exposed to ceramide. The heart in each is denoted by the black arrowhead. (B) Blood vessel development in zebrafish embryos. At the top is a schematic diagram of the zebrafish circulatory system in the trunk region illustrating key structures. (ISA: Intersegmental artery; ISV: Intersegmental vein; DLAV: dorsal longitudinal anastomotic vessel). Blood flows caudally (to the right) via the dorsal aorta (DA), and returns rostrally (to the left) via post cardinal vein (PCV). At the bottom is a brightfield image of blood vessels in a $48 \mathrm{hpf}$ embryo. Dashed lines denote the vessels. (C) Intersegmental blood vessel (ISBV) diameter in the mid-trunk region is altered in zebrafish embryos exposed to ceramide. Top; DMSO- exposed embryo at $48 \mathrm{hpf}$. Bottom; ceramide-exposed embryo at $48 \mathrm{hpf}$. White arrows in both images denote ISBVs. Black arrows point to individual blood cells. D. Quantification revealed that ceramide exposure altered blood flow in $69 \%$ of the embryos examined. Heart rates were also measured and found to be similar in both cases. Lastly, in ceramide exposed embryos, intersegmental blood vessels (ISBVs) that lacked blood flow were significantly thinner in diameter than blood vessels in DMSO control embryos $\left({ }^{*} p<0.01\right)$. Scale bars $=500$ $\mu \mathrm{m}$ in $\mathrm{A}, 20 \mu \mathrm{m}$ in $\mathrm{B}$ and $\mathrm{C}$. 
Ceramide exposure had no significant effect on heart rates in zebrafish embryos analyzed between 40 and $48 \mathrm{hpf}$ (Figure 4D-middle panel). At 40hpf, ceramide-exposed embryos had an average heart rate of 150.3 beats per minute $(n=18)$ compared 155 beats per minute in DMSO controls $(\mathrm{n}=14)$. By $48 \mathrm{hpf}$, the heart rates of DSMSO control embryos averaged 165. 7 beats per minute whereas the heart rates in ceramide-exposed embryos was 170.6 beats per minute ( $\mathrm{n}=14,18$ respectively) and this difference was not statistically significant $(p=0.076)$. Those same embryos were then analyzed to see if they had disrupted blood flow through the ISBVs. In a majority of cases, ceramide-exposed embryos lacked blood flow in the ISBVs. The loss of blood flow through the ISBVs coupled with normal heart rates in ceramide-exposed embryos suggested that the morphology of the blood vessels was altered in those ceramide-exposed embryos.

Analysis of the ISBV diameters from those embryos in which heart rate information was gathered revealed that some, but not all ISBVs were significantly thinner in diameter in the ceramide-exposed embryos (Figure 4C, Figure 4D-right panel). Between $42 \mathrm{hpf}$ and $48 \mathrm{hpf}$, blood flow through the ISBVs was easily detected in control DMSO exposed embryos. The region analyzed was caudal to anal fin at the tip of the yolk sac extension. As the embryo ages, blood flow can be detected in more anterior ISBVs. We analyzed a seven-eight segment region caudal to the anal fin in $48 \mathrm{hpf}$ control and ceramide-exposed embryos. In all DMSO control embryos analyzed in this manner $(n=14)$, robust blood flow was detected in almost all the ISBVs analyzed (111/112). In the ceramide treated embryos, normal blood flow was evident in $66 \%$ of the ISBVs analyzed (99/149). The ISBVs exhibiting no blood flow were significantly thinner in diameter $(4.1 \pm 0.12$ microns, $n=50)$ than the ISBVs of ceramide treated embryos that had robust blood flow through them $(8.66 \pm 0.18$ microns, $n=99$, Figure 4D).

In all of the experiments presented thus far, zebrafish embryos were mobile and quite responsive to touch. Except for the lack of blood flow through the ISBVs, no other abnormal phenotypic effects were detected with light microscopy. There were also no observable morphological changes in DMSO-exposed control embryos. Removal of ceramide and the return of embryos to normal embryo media at $56 \mathrm{hpf}$ failed to restore the blood flow pattern back to normal, as some of the ISBVs still lacked blood flowing through them even when assayed as late as $72 \mathrm{hpf}$.

\section{Ceramide effects on ISBV patterning}

The circulatory system in zebrafish has been extensively studied and the mechanisms of angiogenesis have been well characterized by others $(12,33)$. A developmental timeline highlighting key molecular events during angiogenesis drawn from the literature is illustrated in Figure 5A.

The results presented to this point indicate that the reduced blood flow through ISBVs in ceramide-exposed embryos was due to altered blood vessel development, primarily due to thinning of the vessels and/or altered patterning of the developing vasculature. The intersegmental blood vessels (ISBVs) in zebrafish are arranged in an extremely regular pattern. In the medial-lateral plane, the ISBVs run between the notochord and somite ventrally, while they are restricted between the neural tube and somite boundaries dorsally (12). ISBVs, like motoneuron axons, exhibit regular patterns of organization and this pattern is maintained along both the anterior posterior axis as well as the dorsal ventral axis of the embryo. This pattern, which is established early in development, is highlighted in figure 4B. The ISBVs are evenly spaced from segment to segment and they have a characteristic " $S$ " profile as they extend dorsal to ventral (Figure 4B-bottom-panel, Figure 5E). The ISBVs connect ventrally to either dorsal aorta or posterior cardinal vein, respectively and run dorsally between and adjacent to the notochord, neural tube and the somites (34). The spacing between ventral and dorsal aspects of individual ISBVs is consistent along the anterior posterior axis with no obvious irregularities. Simultaneously, there is a similar patterning of spinal motoneurons being established during development. Axons and blood vessels therefore may make use of common signaling pathways (Figure 5A) often complementing each other utilizing guidance cues which repel or attract developing blood vessels and axons (30).

To determine if blood vessel development was altered by ceramide exposure at developmental time points preceding the onset of blood flow, vessel morphology was investigated in embryos expressing GFP in their vasculature system. The morphology of the GFP-positive ISBVs in ceramide-exposed Fli-1 embryos exhibited abnormal ISBV formation as early as $30 \mathrm{hpf}$ (Figure 5B). There were two major phenotypes observed. 


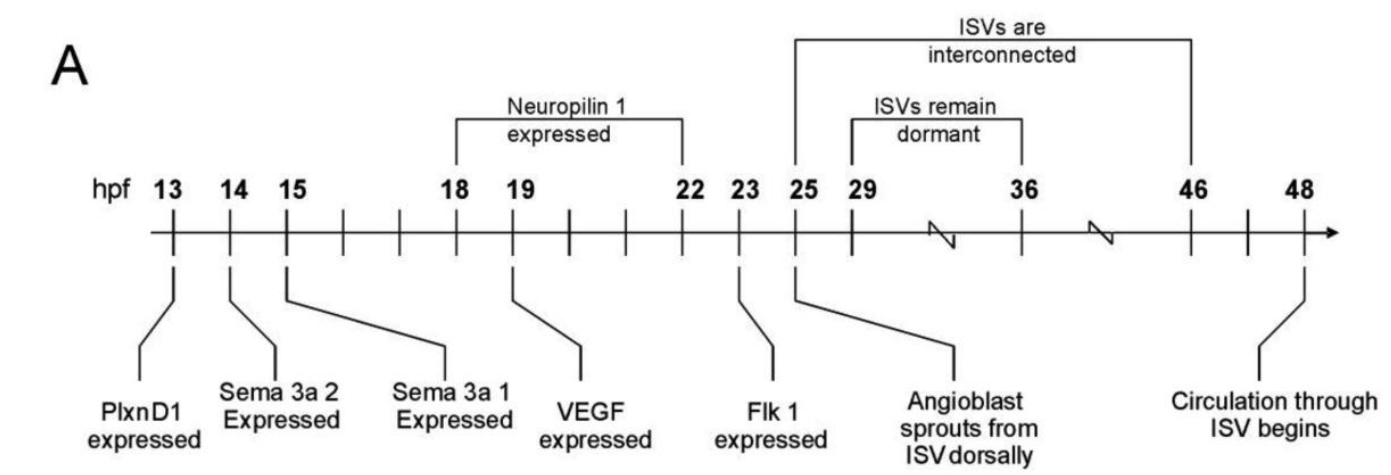

B
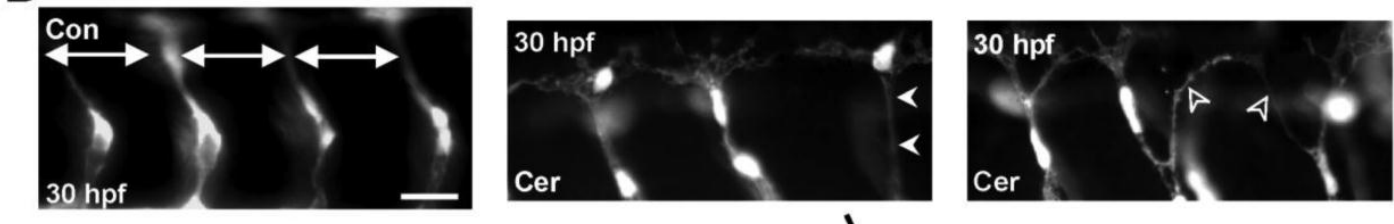

C
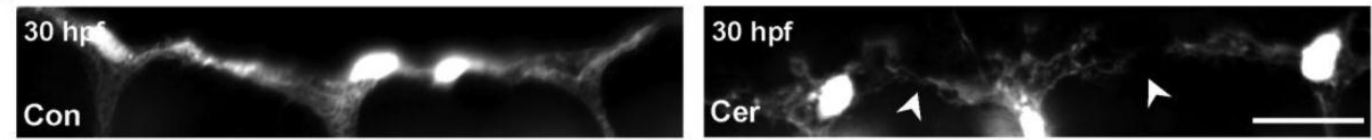

D

$\mathrm{E}$
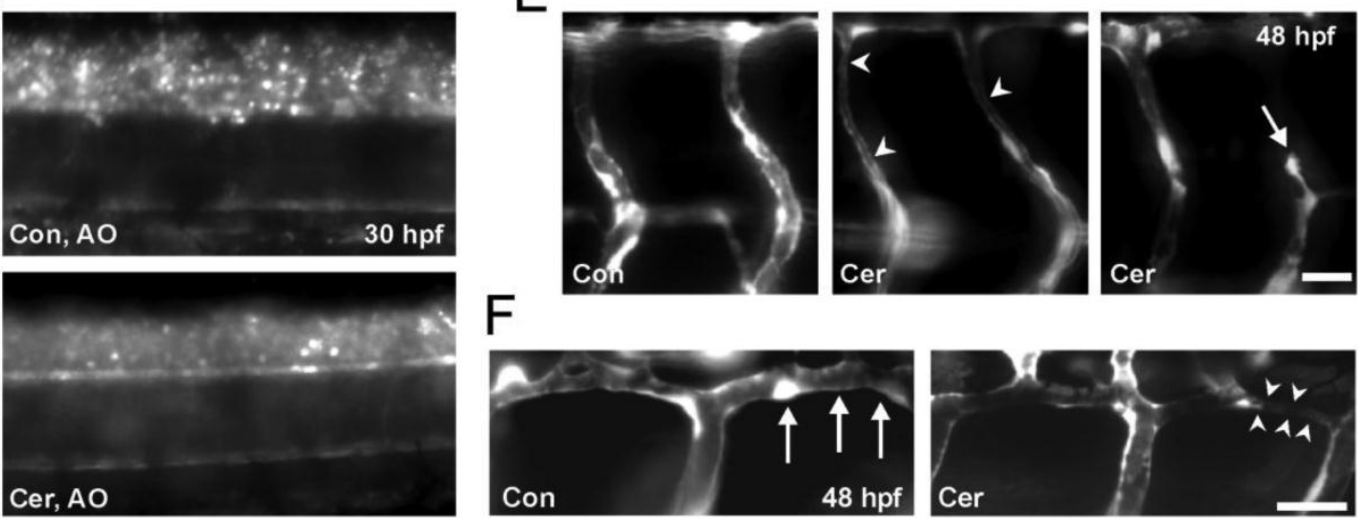

Figure 5. Ceramide inhibits angiogenesis in zebrafish embryos. (A) Developmental timeline of gene expression for particular genes implicated in both angiogenesis and primary motoneuron development in embryonic zebrafish. (B) Left; GFP positive blood vessels in $30 \mathrm{hpf} F$ Fli-1 control embryos. Doral ventral projecting ISBVs develop in a patterned manner and are evenly spaced throughout the length of the embryo. Middle; GFP positive blood vessels in Fli-1 embryos reveal patterning misguidance in embryos exposed to ceramide (white arrowheads). All photomicrographs were obtained from the same 3 segments in the mid trunk region. (C) Higher magnification view of middle panel in $B$ is shown at the right. At the left is DMSO exposed embryo. The DLAV in the ceramide-exposed embryo has not completely formed and has a disorganized appearance. (D) Acridine Orange (AO) staining in $30 \mathrm{hpf}$ control and ceramide exposed embryos. (E) Ceramide exposure in $48 \mathrm{hpf} F(i-1$ embryos results in differing abnormal phenotypes (white arrowheads). ISBVs of a $48 \mathrm{hpf}$ DMSO-exposed (control) zebrafish embryo are shown at the far left. (F) DLAV formation was also effected in $48 \mathrm{hpf}$ ceramide-exposed embryos. Left; DLAV in a 48hpf, DMSO exposed control embryo is denoted by the white arrows. Right; DLAV of ceramide exposed zebrafish embryo. Scale bars in all panels $=20 \mu \mathrm{m}$.

Consistent with observations made with DIC microscopy, these young embryos exhibited thinner ISBVs. Moreover, some vessels did not exhibit the characteristic " $\mathrm{S}$ " profile typical of normal vessels; instead they projected in a straight line from dorsal to ventral (Figure 5B-middle panel) We also detected errors in DLAV formation analogous to what we observed for tube formation in the in vitro studies pre- 
viously presented (Figure 5B-right panel, Figure 5C) The DLAVs did not form precise organized tubes. Instead, they appeared as a tangled meshwork of GFP positive endothelial cells.

We analyzed cermaide-exposed zebrafish embryos to test for the distinct possibility that apoptosis was being up-regulated by ceramide in vivo. Cell death in ceramide-exposed and DMSO control embryos was assessed with Acridine Orange staining in living embryos (Figure 5D). Acridine Orange is a vital dye that has been used in zebrafish to detect cells undergoing cell death $(31,32)$. We performed Acridine Orange staining on both ceramide-exposed and DMSO control embryos (30-36 hpf, n=32 and 28 respectively). We chose this developmental time-point because we first detected changes in blood vessel morphology at $30 \mathrm{hpf}$. Somewhat surprisingly, ceramide did not up-regulate apoptosis in the zebrafish assay when compared to DMSO-exposed embryos. Thus, in the in vivo zebarfish assay, ceramide exposure results in inhibition of angiogenesis but not the initiation of cell death.

Analysis of 48 hpf Fli-1 embryos further validated the results obtained with DIC microscopy for 48 hpf, ceramide-exposed embryos. Some, but not all of the ISBVs as well as DLAVs were thinner in diameter in ceramide-exposed Fli-1 embryos compared to DMSO-exposed embryos (Figure 5E, Figure 5F-middle image). In some cases, ISBVs appeared stalled or stunted in development (Figure 5E, right image) resulting in incomplete vessel formation. These stunted vessels appeared to just stop developing and did not form the appropriate connections with the DLAVs.

\section{Effects of ceramide on primary motoneurons de- velopment in zebrafish}

We first conducted motoneuron axon studies in NBT transgenic zebrafish embryos because their GFP positive, motoneuron axons are easily detectable early on in development. These experiments were conducted because it has been documented that axonal trajectories during CNS development require some of the same guidance cues needed for the patterning of the blood vessel formation $(29,30,35-38)$. Since ceramide exposure had such a profound effect on blood vessel development in zebrafish embryos, we hypothesized that the ceramide exposure would alter motoneuron axonal development.

Three primary motoneurons are present in the developing ventral spinal cords of zebrafish embryos and have been individually identified as the caudal primary $(\mathrm{CaP})$, middle primary $(\mathrm{MiP})$, and rostral primary $(\mathrm{RoP})$ neurons $(39,40)$. A schematic diagram of two of these three primary motoneurons, $\mathrm{CaP}$ and MiP is illustrated in Figure 6A. The axons of the primary motoneurons have been shown to follow specific trajectories to the periphery $(41,42)$. Like blood vessel development in zebrafish, axonal trajectories exhibit a very organized pattern of development. As shown in figure 6A, MiP axons innervating the dorsal periphery are evenly spaced from segment to segment. By 30hpf, the axons have extended to the most distal portion of the periphery. CaP axons follow a similar pattern of organization, but innervate the ventral musculature. Both $\mathrm{MiP}$ and $\mathrm{CaP}$ axons lack branching early in development. These primary motoneurons in zebrafish spinal cord develop at $15 \mathrm{hpf}$ and begin extending axons into the periphery at approximately $17 \mathrm{hpf}$. This is right at the time that VEGF expression first begins to appear in the trunk region of the zebrafish.

Zebrafish embryos exposed to ceramide displayed abnormal primary motoneuron axonal trajectories in all the NBT embryos examined ( $\mathrm{n}=13,30 \mathrm{hpf}$ embryos). Three abnormal phenotypes were evident. $\mathrm{CaP}$ axons (see figure 6A for schematic of these axons) were stunted at the region close to the horizontal myoseptum in the ventral somite region (Figure 6B). Instead of extending into the distal periphery, the axons appeared to stop developing prior to entering the distal periphery. This phenotype was very similar to the stunted blood vessel development caused by ceramide exposure shown in figure $5 \mathrm{E}$. CaP axons in ceramide-exposed embryos, in some instances, made straight-line trajectories into the periphery just like some of the ISBVs in ceramide-exposed embryos. Lastly, $\mathrm{CaP}$ axons in ceramide-exposed embryos exhibited ectopic branching. This was not seen in control embryos (Figure 6B).

The effect of ceramide exposure on MiP axonal trajectories in the NBT transgenic embryos was difficult to assess due to high background of the expressed GFP in the dorsal region of spinal cord. Therefore, we analyzed the effect of ceramide exposure on MiP axons in wildtype embryos by znp1 immunostaining. Znp1 immunostaining also confirmed ceramide effetc on the $\mathrm{CaP}$ axon phenotypes. $\mathrm{CaP}$ axons were stunted in development failing to extend to the distal periphery, took straight-line trajectories to the periphery, or exhibited ectopic branches. All of these abnormal phenotypes were easily detected with the antibody znp1 (Figure 6C, n=18 embryos). Ceramide exposure also caused MiP motoneuron axons to develop ectopic branches (Figure 6D). In some cases, the MiP axons appeared to traverse horizontally along the spinal cord boundary before extending dorsally, which we considered to be an error in path-finding (Figure 6E). 
B
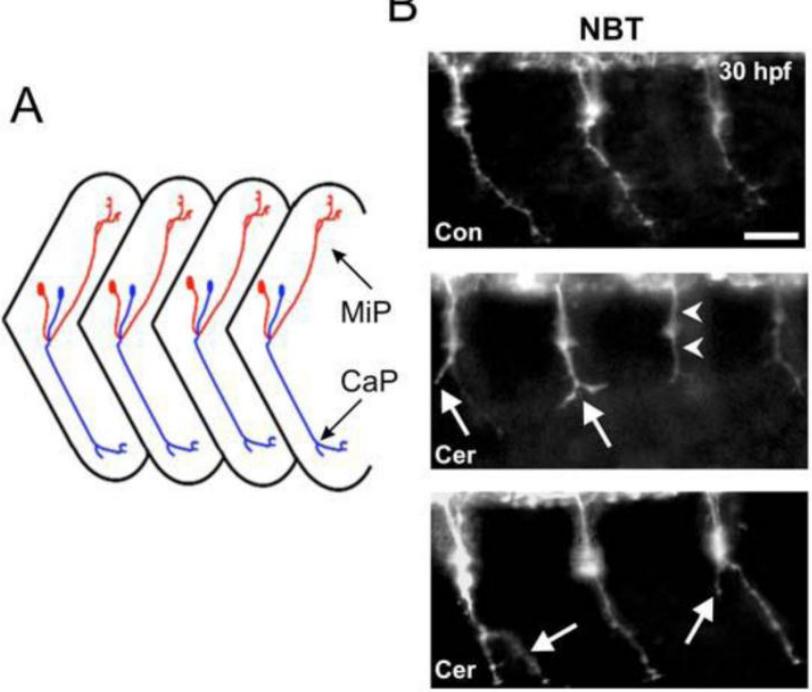

C
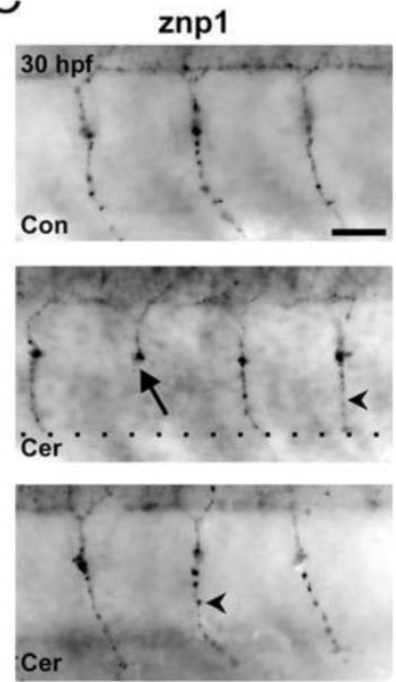

D

E
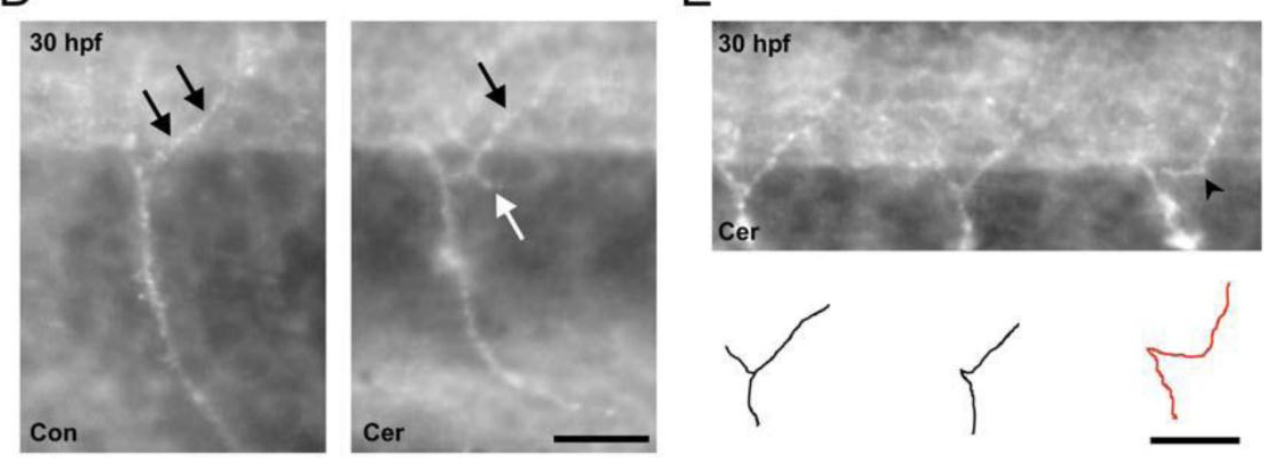

Figure 6. Ceramide alters primary motoneuron axonal pathfinding in zebrafish embryos. (A) Schematic diagram of a lateral view of zebrafish trunk region showing ventral $\mathrm{CaP}$ (blue) and dorsal MiP (red) axonal trajectories. Anterior is to the left, dorsal is toward the top. (B) Top; image of a $30 \mathrm{hpf}$ DMSO-exposed, NBT transgenic zebrafish. GFP positive $\mathrm{CaP}$ axons are easily detected as they project to the periphery. Middle; image of a ceramide-exposed, NBT zebrafish. White arrows denote stunted axons where the CaP axons split into 2 branches. (C) Top; 30 hpf DMSO control embryo stained with the antibody znp1 to detect $\mathrm{CaP}$ axon. Middle and Bottom: Ceramide exposure caused a stunt in CaP axons (black arrow) and also resulted in CaP axons projecting straight out to the periphery (black arrowhead). (D) Left: Magnified image of one segment from a DMSO exposed control embryo in the region of the yolk sac extension. Black arrows denote the MiP axon, which innervates the dorsal periphery. Right: Image of $30 \mathrm{hpf}$, ceramide-exposed embryos. The white arrow points to an ectopic branch projecting off the MiP axon. (E) Another example of a $30 \mathrm{hpf}$ embryo exposed to ceramide. Bottom: Cartoon depicts the primary motoneuron axonal trajectories for the embryo at the top. Scale bar $=20 \mu \mathrm{m}$ in B, C, D and E.

\section{Discussion}

In this study, we set out to demonstrate anti-angiogenic effects of ceramide during development. It has been widely accepted that ceramide causes apoptosis in a variety of cells/tissues (43-45). But only until very recently, has ceramide been implicated in angiogenesis $(13,46,47)$.

Exposure of MCF-7 breast cancer cells to $50 \mu \mathrm{M}$ ceramide for 24 hours caused reductions in cell via- bility and cell migration. Ceramide also inhibited VEGF-induced HUVEC tube formation in culture. Although the levels of VEGF in culture medium containing MCF-7 decreased, cathepsin D levels increased. The results pertaining to cathespin $\mathrm{D}$ indicate that ceramide induces apoptosis in MCF-7 cancer cells.

The fact that the VEGF expression induced by cancer cells, which stimulates the endothelial cells to aid in neo-vascularization, is reduced by ceramide 
exposure suggested that ceramide should be able to inhibit endothelial tube formation in culture and ultimately affect blood vessel formation in vivo. Both of these predictions were validated in this study. In vitro, tube formation in endothelial cells, which is the first step of sprouting, is inhibited by ceramide exposure at concentrations that did not induce apoptosis. These in vitro results clearly support the idea that ceramide has a dual role and thus may be powerful therapy in treating tumors. This study demonstrates that ceramide at high concentrations can initiate apoptosis in some cells including the MC7-cells. Moreover, ceramide exposure also inhibits tube formation in vitro. Ultimately, this would result with the inhibition of tumor progression.

The results from the embryonic chick CAM assay demonstrated a significant reduction of vessel formation within 24 hour of ceramide exposure. To further ascertain the effect of ceramide on the developing vasculature, studies were then conducted in the zebrafish model system. The zebrafish vasculature system is highly conserved and blood vessel formation by angiogenic sprouting requires the same proteins that are necessary for blood vessel growth in mammals $(48,49)$. Our results clearly demonstrate that ceramide exposure alters vasculature development as well as motoneuron axonal pathfinding in zebarfish. Importantly, ceramide exposure did not induce apoptosis in zebrafish.

The angiogenic-patterning defect observed by ceramide treatment of zebrafish may be mediated by loss of VEGF expression, consistent with our in vitro observations. The VEGF downregulation by ceramide may also contribute to axonal pathfinding difficulties. However, there are several other possibilities by which ceramide exposure could regulate axonal pathfinding. First, ceramide may affect axonal patterning by interacting with the Shh or BMP pathways (15). Secondly, ceramide could potentially regulate endothelial cell development and axonal guidance simultaneously, simply by altering neuropilin expression (13). Lastly, altering VEGF and or VEGF receptor levels could have a profound impact on both vascular system and nervous system development. Our in vitro studies clearly indicate that ceramide causes a down regulation of VEGF. The semaphorins, which are axonal guidance molecules and have been identified in zebrafish, bind to the VEGF receptor to facilitate axonal pathfinding. If VEGF receptor levels are reduced, the semaphorins would not likely be able to exert their inhibitory effects during motoneuron development and axonal pathfinding. Future studies are needed to investigate these intriguing possibilities.
Our results are in agreement with the recent studies investigating the factors that guide growth cone extensions that can also regulate migration of putative angioblasts. VEGF regulates angioblast migration and is involved in axonal pathfinding (50). Recent studies on glycoproteins such as neuropilin-1 (NRP1) and neuropilin-2 (NRP2) have been implicated in regulating both the semaphorins in neuronal guidance and vascular endothelial growth factor (VEGF) in angiogenesis (51). It may be the case that ceramide can also directly regulate the levels of axonal guidance factors in zebrafish such as semaphorins, ephrins and netrins, and growth factors such as VEGF, EGF, bFGF. All these possibilities require further exploration.

In conclusion, we have demonstrated a dual role of ceramide in rendering the breast cancer cells apoptotic as well as inhibiting tumor-induced angiogenesis. In vivo, ceramide does not appear to induce apoptosis, but does affect angiogenesis. These findings are novel as they clearly demonstrate a dual role for ceramide in potentially containing tumor growth not only by directly affecting the tumor proliferation via the induction of apoptosis, but also by preventing its growth and metastasis by inhibiting the development of the vasculature that provides nutrients to the growing tumor. This is a very important distinction that we argue should not be overlooked. In the context of a developing tumor, therapeutic treatments that simply induce apoptosis, may on one hand cease the progression of the tumor but may have deleterious side effects associated with inducing other non-cancerous cells into the apoptotic pathway. This may not be a good thing. On the other-hand, blood vessel development and recruitment of blood vessels that provide nourishment to a tumor is a developmental phenomenon. This process of angiogenesis, if specifically disrupted would ultimately result in the starvation of a growing tumor, but not yield deleterious side effects. Exposure to ceramides at concentrations that did not induce apoptosis would still inhibit any angiogenic events and likely nothing else. We also predict that ceramide exposure would have little effect on an established vasculature system, just a developing one, making for a potentially powerful cancer therapeutic producing little if any side effects in adult organism.

\section{Conflict of Interests}

The authors have declared that no conflict of interest exists. 


\section{References}

1. Ogretmen B, Hannun YA. Biologically active sphingolipids in cancer pathogenesis and treatment. Nat Rev Cancer. 2004; 4(8): 604-16.

2. Lemonnier LA, Dillehay DL, Vespremi MJ, et al. Sphingomyelin in the suppression of colon tumors: prevention versus intervention. Arch Biochem Biophys. 2003; 419(2): 129-38.

3. Struckhoff AP, Bittman R, Burow ME, et al. Novel ceramide analogs as potential chemotherapeutic agents in breast cancer. $\mathrm{J}$ Pharmacol Exp Ther. 2004; 309(2): 523-32.

4. Cai Z, Bettaieb A, Mahdani NE, et al. Alteration of the sphingomyelin/ceramide pathway is associated with resistance of human breast carcinoma MCF7 cells to tumor necrosis factor-alpha-mediated cytotoxicity. J Biol Chem. 1997; 272(11): 6918-26.

5. Radin NS. Killing tumours by ceramide-induced apoptosis: a critique of available drugs. Biochem J. 2003; 371(Pt 2): 243-56.

6. Scarlatti F, Bauvy C, Ventruti A, et al. Ceramide-mediated macroautophagy involves inhibition of protein kinase B and up-regulation of beclin 1. J Biol Chem. 2004; 279(18): 18384-91.

7. Stover TC, Sharma A, Robertson GP, Kester M. Systemic delivery of liposomal short-chain ceramide limits solid tumor growth in murine models of breast adenocarcinoma. Clin Cancer Res. 2005; 11(9): 3465-74.

8. Bourbon NA, Sandirasegarane L, Kester M. Ceramide-induced inhibition of Akt is mediated through protein kinase Czeta: implications for growth arrest. J Biol Chem. 2002; 277(5): 3286-92.

9. Chalfant CE, Szulc $\mathrm{Z}$, Roddy $\mathrm{P}$, et al. The structural requirements for ceramide activation of serine-threonine protein phosphatases. J Lipid Res. 2004; 45(3): 496-506.

10. Chintalapati $M$, Truax $R$, Stout $R$, et al. In vitro and in vivo anti-angiogenic activities and inhibition of hormone-dependent and -independent breast cancer cells by ceramide methylaminoethylphosphonate. J Agric Food Chem. 2009; 57(12): 5201-10.

11. Carmeliet P. Angiogenesis in health and disease. Nat Med. 2003; 9(6): 653-60.

12. Childs S, Chen JN, Garrity DM, Fishman MC. Patterning of angiogenesis in the zebrafish embryo. Development. 2002; 129(4): 973-82.

13. Yabu T, Tomimoto $H$, Taguchi $Y$, et al. Thalidomide-induced antiangiogenic action is mediated by ceramide through depletion of VEGF receptors, and is antagonized by sphingosine-1-phosphate. Blood. 2005; 106(1): 125-34.

14. Chedotal A, Kerjan G, Moreau-Fauvarque C. The brain within the tumor: new roles for axon guidance molecules in cancers. Cell Death Differ. 2005; 12(8): 1044-56.

15. Carmeliet P. Blood vessels and nerves: common signals, pathways and diseases. Nat Rev Genet. 2003; 4(9): 710-20.

16. Munafo DB, Colombo MI. A novel assay to study autophagy: regulation of autophagosome vacuole size by amino acid deprivation. Journal of cell science. 2001; 114(Pt 20): 3619-29.

17. Katsumoto M, Shingu T, Kuwashima R, et al. Biphasic effect of HMG-CoA reductase inhibitor, pitavastatin, on vascular endothelial cells and angiogenesis. Circ J. 2005; 69(12): 1547-55.

18. Sprague J, Doerry E, Douglas S, Westerfield M. The Zebrafish Information Network (ZFIN): a resource for genetic, genomic and developmental research. Nucleic Acids Res. 2001; 29(1): 87-90.

19. Svoboda KR, Linares AE, Ribera AB. Activity regulates programmed cell death of zebrafish Rohon-Beard neurons. Development. 2001; 128(18): 3511-20.

20. Svoboda KR, Vijayaraghavan S, Tanguay RL. Nicotinic receptors mediate changes in spinal motoneuron development and axonal pathfinding in embryonic zebrafish exposed to nicotine. J Neurosci. 2002; 22(24): 10731-41.

21. Johnson MD, Torri JA, Lippman ME, Dickson RB. The role of cathepsin D in the invasiveness of human breast cancer cells. Cancer Res. 1993; 53(4): 873-7.

22. Heinrich M, Wickel M, Schneider-Brachert W, et al. Cathepsin $\mathrm{D}$ targeted by acid sphingomyelinase-derived ceramide. Embo J. 1999; 18(19): 5252-63.

23. Heinrich $M$, Wickel $M$, Winoto-Morbach S, et al. Ceramide as an activator lipid of cathepsin D. Adv Exp Med Biol. 2000; 477: 305-15.

24. Emert-Sedlak L, Shangary S, Rabinovitz A, et al. Involvement of cathepsin D in chemotherapy-induced cytochrome c release, caspase activation, and cell death. Mol Cancer Ther. 2005; 4(5): 733-42.

25. Fry MJ. Phosphoinositide 3-kinase signalling in breast cancer: how big a role might it play? Breast Cancer Res. 2001; 3(5): 304-12.

26. Lavieu G, Scarlatti F, Sala G, et al. Is autophagy the key mechanism by which the sphingolipid rheostat controls the cell fate decision? Autophagy. 2007; 3(1): 45-7.

27. Biederbick A, Kern HF, Elsasser HP. Monodansylcadaverine (MDC) is a specific in vivo marker for autophagic vacuoles. Eur J Cell Biol. 1995; 66(1): 3-14.

28. Ribatti D, Vacca A, Roncali L, Dammacco F. The chick embryo chorioallantoic membrane as a model for in vivo research on anti-angiogenesis. Curr Pharm Biotechnol. 2000; 1(1): 73-82.

29. Autiero M, De Smet F, Claes F, Carmeliet P. Role of neural guidance signals in blood vessel navigation. Cardiovasc Res. 2005; 65(3): 629-38

30. Carmeliet $\mathrm{P}$, Tessier-Lavigne $\mathrm{M}$. Common mechanisms of nerve and blood vessel wiring. Nature. 2005; 436(7048): 193-200.

31. Reimers MJ, La Du JK, Periera CB, Giovanini J, Tanguay RL. Ethanol-dependent toxicity in zebrafish is partially attenuated by antioxidants. Neurotoxicol Teratol. 2006; 28(4): 497-508.

32. Hill A, Howard CV, Strahle U, Cossins A. Neurodevelopmental defects in zebrafish (Danio rerio) at environmentally relevant dioxin (TCDD) concentrations. Toxicol Sci. 2003; 76(2): 392-9.

33. Torres-Vazquez J, Gitler AD, Fraser SD, et al. Semaphorin-plexin signaling guides patterning of the developing vasculature. Dev Cell. 2004; 7(1): 117-23.

34. Isogai S, Lawson ND, Torrealday S, et al. Angiogenic network formation in the developing vertebrate trunk. Development. 2003; 130(21): 5281-90.

35. Garthwaite G, Bartus K, Malcolm D, et al. Signaling from blood vessels to CNS axons through nitric oxide. J Neurosci. 2006; 26(29): 7730-40.

36. Eichmann A, Le Noble F, Autiero M, Carmeliet P. Guidance of vascular and neural network formation. Curr Opin Neurobiol. 2005; 15(1): 108-15.

37. Eichmann A, Makinen T, Alitalo K. Neural guidance molecules regulate vascular remodeling and vessel navigation. Genes Dev. 2005; 19(9): 1013-21.

38. Bearden SE, Segal SS. Microvessels promote motor nerve survival and regeneration through local VEGF release following ectopic reattachment. Microcirculation. 2004; 11(8): 633-44.

39. Eisen JS, Pike SH, Debu B. The growth cones of identified motoneurons in embryonic zebrafish select appropriate pathways in the absence of specific cellular interactions. Neuron. 1989; 2(1): 1097-104.

40. Westerfield M, McMurray JV, Eisen JS. Identified motoneurons and their innervation of axial muscles in the zebrafish. J Neurosci. 1986; 6(8): 2267-77.

41. Hjorth J, Key B. Development of axon pathways in the zebrafish central nervous system. Int J Dev Biol. 2002; 46(4): 609-19. 
42. Lewis KE, Eisen JS. From cells to circuits: development of the zebrafish spinal cord. Prog Neurobiol. 2003; 69(6): 419-49.

43. Thevissen K, Francois IE, Winderickx J, et al. Ceramide involvement in apoptosis and apoptotic diseases. Mini Rev Med Chem. 2006; 6(6): 699-709.

44. Lin CF, Chen CL, Lin YS. Ceramide in apoptotic signaling and anticancer therapy. Curr Med Chem. 2006; 13(14): 1609-16.

45. Siskind LJ, Kolesnick RN, Colombini M. Ceramide forms channels in mitochondrial outer membranes at physiologically relevant concentrations. Mitochondrion. 2006; 6(3): 118-25.

46. Blazquez C, Gonzalez-Feria L, Alvarez L, et al. Cannabinoids inhibit the vascular endothelial growth factor pathway in gliomas. Cancer Res. 2004; 64(16): 5617-23.

47. Erdreich-Epstein A, Tran LB, Bowman NN, et al. Ceramide signaling in fenretinide-induced endothelial cell apoptosis. J Biol Chem. 2002; 277(51): 49531-7.

48. Vogel AM, Weinstein BM. Studying vascular development in the zebrafish. Trends Cardiovasc Med. 2000; 10(8): 352-60.

49. Isogai S, Horiguchi M, Weinstein BM. The vascular anatomy of the developing zebrafish: an atlas of embryonic and early larval development. Dev Biol. 2001; 230(2): 278-301.

50. Shoji W, Isogai $S$, Sato-Maeda $M$, et al. Semaphorin3a1 regulates angioblast migration and vascular development in zebrafish embryos. Development. 2003; 130(14): 3227-36.

51. Negishi M, Oinuma I, Katoh H. Plexins: axon guidance and signal transduction. Cell Mol Life Sci. 2005; 62(12): 1363-71. 